\title{
Surface thermodynamic parameters of modified wood
}

\author{
Elena Pokrovskaya ${ }^{1}$, Fedor Portnov ${ }^{1 *}$, Andrey Dolganov ${ }^{2}$ \\ ${ }^{1}$ Moscow State University of Civil Engineering, 129337, 26, Yaroslavskoye Shosse, Moscow, \\ Russian Federation \\ ${ }^{2}$ Zhilekspertiza, 127055, ul. Yablochkov, 21 building 3, Moscow, Russia
}

\begin{abstract}
Energy characteristics of modified wood are studied in the paper. Application of this approach during the study of wooden materials allows forecasting the efficiency of modifiers for surface layer of wood. Phosphites, the efficient fire-retarders, were applied as modifiers. Using the example of a number of ethers with various alkoxy substituents of phosphorus atom, we have made an attempt to associate surface thermodynamic properties of modified wood and formation of properties for fire-, bio- and smoke protection. The dependence of change of energy characteristics and surface structure of wood on the nature of modifiers is determined. To study energy characteristics of wood, modified by various compounds, the following characteristics were used: $\sigma$ surface tension and $\Delta \mathrm{G}$ free enthalpy gradient. Easy Drop setting and the corresponding software were used to determine these values. According to the obtained data, the conclusion is made about the influence of modifiers on energy characteristics of wood. The high degree of modification (\% P) causes bigger change of Gibbs energy, which determines formation of high-level fire-, bio- and smoke protection. Diethyl phosphite is the most efficient modifier. Formation of fire-protective properties stipulates long-term operation of wood and wood-based materials.
\end{abstract}

\section{Introduction}

Wood is a renewable material of high strength and aesthetic qualities. Wood constructions (WC), laminated wood constructions (LWC) and board materials are used as construction materials.

Wood has platelet structure with hydrophilic surface. Hydrolytic processes develop at $18-20 \%$ moisture content of wood, leading to its destruction. Hydrolysis processes accelerate significantly in the presence of wood-destroying fungi, biocorrosion develops [1].

The main wood components are cellulose and lignin - combustible organic polymers. Burning quality and low biostability of wood reduce its operational properties $[15,16]$.

\footnotetext{
* Corresponding author: romeo-aleks@yandex.ru
} 
Modification of the materials, including wood, allows enhancing its operational properties, durability of wood and wood constructions. Studying these processes is a task of urgent character.

The papers [2-6] show that wood can obtain fire- and bio-protection and hydrophobic properties due to surface chemical modification by organophosphorous compounds.

Surface modification by organophosphorous compounds proceeds in 1-2 mm surface layer of wood. At the same time, wood acquires enhanced operational and fire-protective properties. Efficient modifiers should react with $\mathrm{OH}$-group supporter of lignin-carbohydrate complex components; the degree of reaction cannot be above $0.8-1.5 \%$ of chemically combined phosphorus [13, 14].

Determining factors that allow increasing modification process is an urgent task.

Surface modification depends on surface energy characteristics; the following thermodynamic parameters are suggested as quantitative characteristics for surface properties: ultimate surface tension and free enthalpy gradient. The factor of surface energy degree is surface tension [7]. The calculation of free enthalpy gradient of modified surface has been carried out on the basis of joint laws of thermodynamics I and II [8-9].

For the calculation of free surface energy for systems with constant chemical composition the joint equation of laws of thermodynamics I and II is the following:

$$
d G=-S d T+V d p+\sigma d S_{y d}+\mu d n
$$

Where $G$ is Gibbs energy, $S$ is entropy of the system, $T$ is temperature, $V$ is volume, $p$ is pressure, $\sigma$ is surface tension (work of surface formation per unit), Sud is specific surface, $\mu$ is chemical potential of the matter, composing condensed phase, $n$ is the number of moles.

Under the free enthalpy conditions and at fixed amount of matter the equation is the following:

$$
d G=\sigma d S_{y \partial}
$$

The surface tension of a solid body measures the inner energy of the whole system, reduced to the unit of material surface. As the free enthalpy gradient is a function of the system state, its total differential is as follows:

$$
\Delta G=\sigma d S_{y \partial}+S_{y \partial} d \sigma
$$

On the basis of the given equations and published works we set a task to examine the changing energy parameters of the surface of wood after modification as well as examine relationship of the change $\Delta G$ with such wood properties like degree of modification, adsorption capacity, smoke generation ability, fire resistance.

The total improvement of these properties relative to the original wood can ensure reliability and durability of wood material and wooden structures.

Study of surface modification of wood provides an opportunity to assess in advance effectiveness of surface layer modifiers using thermodynamic quantities $(\Delta G, \sigma)$.

\section{Experimental part}

Determination of thermodynamic characteristics was conducted on pine sapwood samples with the size of $40 \times 40 \times 10 \mathrm{~mm}$, humidity of samples was $8 \%$. 20\% solutions of phosphorous acid esters were used as modifiers (dimethylphosphite (DMF), diethylphosphite (DEP), dipropylphosphite (DPF), dibutylphosphite (DBP)). Increase of 
wood fire resistance after modification of the listed modifiers is noted in the literature.

The goal of the work was to identify changes in Gibbs thermodynamic potential of modified wood surface depending on the modifiers of the surface layer, as well as in defining link between energy characteristics and physical-chemical properties of the modified samples.

Modifiers were applied to the surface of samples in two layers, at temperatures 20-25 $\mathrm{oC}$, modifier consumption was $300 \mathrm{~g} / \mathrm{m} 2$. After modification the samples were put into Soxhlet apparatus. The samples were dried in a drying cabinet at temperature $50 \mathrm{oC}$ for 6 hours, after that the samples were put outside and dried at temperature $25 \mathrm{oC}$ for 7 days.

Surface tension $\sigma$ was determined by neutral drop method [10,11] on EasyDrop station and related software. Values of Sud of wood samples were obtained on NOVA 2200 station by nitrogen sorption.

$\Delta G$ calculation was conducted as follows. On the EasyDrop station the dependence $\cos \theta=\mathrm{f}(\sigma \mathrm{zh})$ of contact angle from standard surface tension of a drop of aqueous ethanol solutions of different concentrations in the form of average straight line (Figure 1).

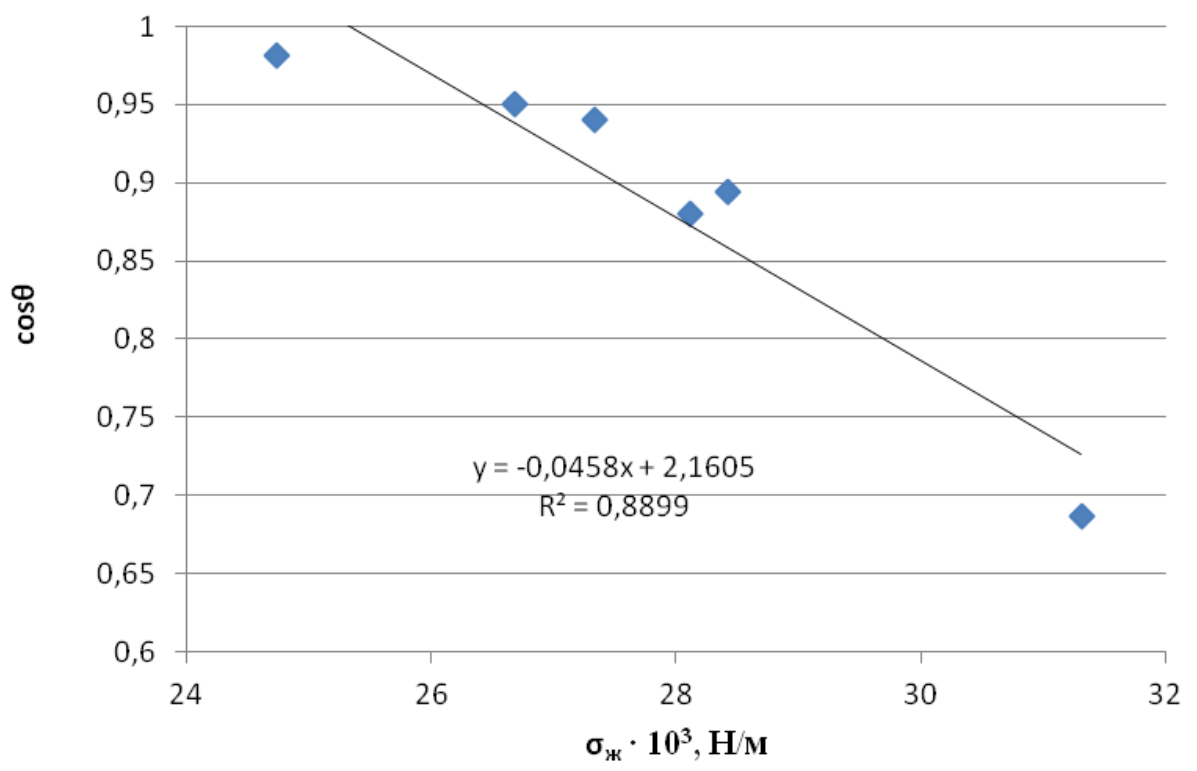

Fig. 1. Diagram of dependence $\cos \theta=\mathrm{f}(\sigma \mathrm{zh})$ for wood surface modified with DMF, where $\mathrm{y}=$ $0.0458 x+2.1605$ - is an equation of a straight line, R2-squared value.

Extrapolating the equation of a straight line up to 1, you can determine the critical value of surface tension $\sigma$, which is a characteristic of the surface energy of the surface unit. According to the obtained data Sud and $\sigma$ the calculation of the free enthalpy gradient is made.

To assess operational characteristics of modified wood data has been obtained on smoke production ability (GOST 12.1.044-89 p. 4.18), fire protection (GOST R 53292-2009, GOST 12.1.044 - 89 p. 4.3, GOST 12.1.044-89 p. 4.19), percentage of phosphorus in a surface level of modified wood (element analysis method), water vapor sorption [12]

The obtained experimental data is collected in Table 1. 
Table 1. Summary experimental data.

\begin{tabular}{|c|c|c|c|c|c|c|}
\hline & \multicolumn{6}{|c|}{ Surface modifier } \\
\hline & DMF & DEP & DFT & DBP & DFF & $\begin{array}{c}\text { PFA- } \\
1\end{array}$ \\
\hline $\begin{array}{l}\text { \%P before thermal } \\
\text { decomposition }\end{array}$ & 2.87 & 3.57 & 2.6 & 2.65 & 2.45 & 2.11 \\
\hline$\% \mathrm{P}$ after thermal decomposition & 0.85 & 4.7 & 0.63 & 0.71 & 1.06 & 0.35 \\
\hline $\begin{array}{c}\Delta \mathrm{G}, \mathrm{J} \\
\text { before thermal decomposition }\end{array}$ & -12.68 & -14.5 & -4.94 & -6.97 & -10.16 & -2.71 \\
\hline $\begin{array}{l}\qquad \Delta \mathrm{G}, \mathrm{J} \\
\text { after thermal decomposition }\end{array}$ & 14.31 & -14.48 & 4.05 & 2.43 & -13.69 & 12.35 \\
\hline $\begin{array}{l}\sigma_{\mathrm{k}} \cdot 10^{3}, \mathrm{n} / \mathrm{m} \\
\text { before thermal decomposition }\end{array}$ & 19.91 & 25.03 & 21.97 & 22.36 & 23.03 & 20.05 \\
\hline $\begin{array}{c}\sigma_{\mathrm{k}} \cdot 10^{3}, \mathrm{n} / \mathrm{m} \text { after thermal } \\
\text { decomposition }\end{array}$ & 19.07 & 24.06 & 116.99 & 17.36 & 19.07 & 22.24 \\
\hline $\begin{array}{l}\qquad \mathrm{a}_{\mathrm{m}}, \% \\
\text { before thermal decomposition }\end{array}$ & 155.5 & 215.8 & 221.9 & 193.4 & 163.52 & 188.6 \\
\hline $\mathrm{Dm}, \mathrm{m} 2 / \mathrm{kg}$ & $\begin{array}{l}450- \\
470\end{array}$ & $\begin{array}{l}130- \\
140\end{array}$ & $640-680$ & $600-640$ & $740-780$ & $\begin{array}{c}400- \\
440\end{array}$ \\
\hline$\Delta \mathrm{m} \%$ & 6.9 & 8.5 & 12.3 & 11.5 & 9.5 & 8.7 \\
\hline
\end{tabular}

As it is shown in Table 1, hydrophilic properties decrease at surface modification by phosphites. The nature of modifier influences hydrophilic properties. The degree of chemical modification of wood also depends on the modifiers nature: the greatest in cases when DMF and DEP are used. Chemical modification is an ester exchange reaction on the hydroxyl groups of cellulose and lignin:

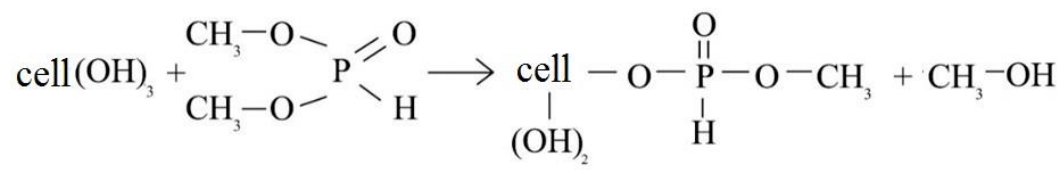

Due to chemical reaction modifier thickens the capillary walls, reducing Sud and water adsorption. Decreased hydrophilic properties result in increase of biostability. Basing on data for loss of mass during thermal decomposition it has been found that DMF and DEF provide the group I of fire-resistance rating.

The change of wood properties at surface modification is determined by surface energy characteristics [7]. The formation of stable chemical bonds, characterized by the most negative values of free enthalpy gradient predetermines the long-term protective effect of modifiers (fire-, bioprotection, ageing resistance, decreased water adsorption, smoke resistance). 


\section{References}

1. E. Pokrovskaya, Y. Kovalchuk, Biological corrosion, 212 (2013)

2. E. Pokrovskaya, Wooden architecture, 136 (2009)

3. E. Pokrovskaya, Chemico-physical principles, 104 (2003)

4. E. Pokrovskaya, F. Portnov, A. Kobelev, D. Korolchenko, FES, 10 (2013)

5. A. Stenin, CFLE Conference proceedings, 553-559 (2013)

6. I. Koteneva, CFLE Conference proceedings, 191 (2011)

7. V. Rodulgin, Physico-Chemistry of surfaces, 121-127 (2011)

8. A.Tutygin, A.Shinkaruk, A.Aisenstadt, V.Lesovik, Ecological risks, 8 (2014)

9. A. Eisenstadt, IMTCECC, 244 (2014)

10. B.Deryagin, I.Abrikosva, E.Lifshitz, PSSS, 494-526 (1958)

11. B.Deryagin, N.Churaev, Wetting film (1984)

12. N.Keltsev, Fundamentals of adsorption technology, 592 (1984)

13. I.V. Stepina, V.I. Sidorov, Applied Mechanics and Materials, 584-586 (2014)

14. I.V. Stepina, V.I. Sidorov, O.A. Klyachenkova, Applied Mechanics and Materials, 584-586 (2014)

15. I.V. Stepina, O.A. Klyachenkova, Procedia Engineering, 91 (2014)

16. L. Grigorieva, P. Oleinik, Solid State Phenomena, 871 (2016) 